\title{
Case report: Over-substitution of thyroxine due to interference in serum thyroid-stimulating hormone measurement
}

\author{
Annette Schollen ${ }^{1,2, *}$, Christine Spitzweg ${ }^{1,2}$ \\ and Michael Vogeser ${ }^{1,2}$ \\ ${ }^{1}$ Institute of Clinical Chemistry, University of \\ Munich, Munich, Germany \\ ${ }^{2}$ Department of Internal Medicine II, Klinikum \\ Großhadern, Ludwig-Maximilians-University Munich, \\ Munich, Germany
}

Keywords: immunoassay; interference; thyroidstimulating hormone.

A 70-year-old female patient underwent thyroidectomy and thyroablative radioiodine treatment for folliculary thyroid cancer with pulmonary metastases (pT1, NO, M1). For thyroid hormone replacement therapy, serum thyroid-stimulating hormone (TSH) concentrations were aimed to be below the lower limit of quantification of the assay $(<0.03 \mu \mathrm{U} / \mathrm{mL})$ with concentrations of free thyroxine and free triiodothyronine within the reference range. For TSH measurements, the Elecsys immunoanalyzer system (Roche Diagnostics, Mannheim, Germany) was used in the routine endocrinological laboratory of our institute. TSH suppression is usually achieved with daily thyroxine doses of approximately 1.5 and $2.0 \mu \mathrm{g} / \mathrm{kg}$. In the patient reported herein, the starting dose of $150 \mu \mathrm{g} /$ day was repeatedly increased, as TSH was constantly found detectable. Under a dose of $300 \mu \mathrm{g}$ thyroxine/day, a TSH concentration of $0.2 \mu \mathrm{U} / \mathrm{mL}$ was measured. At this time, free serum thyroxine was increased with $2.9 \mathrm{ng} / \mathrm{dL}(37.33 \mathrm{pmol} / \mathrm{L})$ (reference range: $0.9-1.9 \mathrm{ng} / \mathrm{dL}(11.58-24.46 \mathrm{pmol} / \mathrm{L})$ and the patient complained about symptoms consistent with thyrotoxicosis. The constellation of hyperthyroid symptoms along with increased thyroid hormone concentrations in the presence of TSH levels only slightly below the normal range was found implausible. Therefore, TSH was re-analyzed using a different immunoassay system, implemented in the short turnaround time laboratory of the institute (Centaur TSH assay, Bayer Diagnostics, Tarrytown, NY, USA). Using this assay, TSH levels were below the lower limit of quantification. Consequently, interference of TSH measurement was noted in this case, and the dosage

*Corresponding author: Annette Schollen, MD, Institute of Clinical Chemistry, University of Munich, Marchioninistraße 15, 81377 Munich, Germany

Phone: + 49-89-7095-3221, Fax: +49-89-7095-1454,

E-mail: Annette.Schollen@med.uni-muenchen.de of thyroxine substitution was reduced to $200 \mu \mathrm{g} / \mathrm{day}$, resulting in euthyroidism. For further follow-up, the Centaur immunoanalyzer system was used for samples from this patient.

Tests of the patient's serum for human anti-mouse antibodies and for rheumatoid factors were negative.

When analyzing another serum sample from this patient during a follow-up visit 3 years after our first observation, again only slightly decreased TSH levels were reported using the Roche Elecsys analyzer $(0.16 \mu \mathrm{U} / \mathrm{mL})$, while TSH remained undetectable with the Bayer Centaur assay.

It is well recognized that all immunoassays are subjected to interferences $(1,2)$. Today, immunologic interference is probably rare compared to some years ago, owing to the addition of blocking agents to the reagent mixtures; however, these interferences are not yet fully resolved. Analytical interference is typically suspected if extremely high or low results are observed; the presence of interference resulting in more or less normal values - as was the case in our patient - is probably detected in far less cases. Nevertheless, in the case described here, assay interference resulted in a relevant but fortunately reversible complication (iatrogenic hyperthyroidism).

Després and Grant (2) reviewed the clinical consequences of failure to recognize interferences in thyroid assays. They reviewed the nature of these disturbances; their occurrence, prevalence, and detection; and the clinical consequences of the failure to recognize such interference. Mostly, heterophilic antibodies are involved in TSH assay disturbance, especially human anti-mouse antibodies and rheumatoid factors can cause interferences by immunoglobulin aggregation, and (or) cross-linking of both capture and signal antibodies (3).

The authors claimed that only a minority of samples demonstrate substantial thyroid assay interferences (2).

Ismail et al. (4) studied 5310 patients with inconsistent TSH results referring to clinical details and analytical results. The samples were re-tested in three follow-up assays (doubling dilutions assay, blocking agents, and repeat analyses using another assay). Incorrect analytical results due to heterophilic antibodies were found in only 28 samples $10.53 \%$ of all samples). The study showed that none of the three follow-up procedures could exclude interferences with total confidence. Thus, in most cases the source of immunoassay interference cannot be specified.

The case described here should encourage physicians to communicate inconsistent test results to the 
responsible clinical laboratory units. In suspect analyses, applying an alternative assay is probably the best method to disclose immunoassay interferences in individual cases. Thus, availability of alternative methods is most desirable for key clinical chemistry analytes. Availability of such an alternative assay within an individual laboratory is clearly an exception, but shipment of samples to co-operating institutions should be institutionalized in such cases $(5,6)$. Testing the linearity of dilution may be another method to disclose assay interferences.

\section{References}

1. Bjerner J, Børmer OP, Nustad K. The war on heterophilic antibody interference. Clin Chem 2005;51:9-11.
2. Després N, Grant A. Antibody interference in thyroid assays: a potential for clinical misinformation. Clin Chem 1998;44:440-54.

3. Bjerner J, Olsen KH, Børmer OP, Nustad K. Human heterophilic antibodies display specificity for murine lgG subclasses. Clin Biochem 2005;38:465-72.

4. Ismail A, Walker PL, Barth JH, Lewandowski KC, Jones R, Burr WA. Wrong biochemistry results: two case reports and observational study in 5310 patients on potentially misleading thyroid-stimulating hormone and gonadotropin immunoassay results. Clin Chem 2002;48:2023-9.

5. Jahagirdar VR, Strouhal P, Holder G, Gama R, Singh BM. Thyrotoxicosis factitia masquerading a recurrent Graves' disease: endogenous antibody immunoassay interference, a pitfall for the unwary. Ann Clin Biochem 2008;45: $325-7$.

6. Monchamp T, Chopra IJ, Wah DT, Butch AW. Falsely elevated thyroid hormone levels due to anti-sheep antibody interference in an automated electrochemiluminescent immunoassay. Thyroid 2007;17:271-5. 